\title{
ESTADO ACTUAL DE LA REFORMA AL SISTEMA PENITENCIARIO EN CHILE
}

\begin{abstract}
Jonatan Mauricio Valenzuela*
1. Introducción; 2. Estado actual de la regulación penitenciaria chilena a la luz de ciertos ejemplos latinoamericanos; 2.1. Regulación penitenciaria general; 2.2. Establecimientos penitenciarios; 3. Principales aspectos para la reforma al sistema penitenciario chileno: 3.1. Existencia de una ley de ejecución de penas; 3.2. Existencia de control administrativo y judicial (especial) en el ámbito penitenciario; 3.3. Procedimiento ante el juez. de ejecución. 4. Diagnóstico.
\end{abstract}

\section{Introducción}

Es una frase común aquella que señala que las personas sometidas al ámbito penitenciario se encuentran en una situación de fuerte desprotección de sus derechos fundamentales, específicamente de aquellos que, considerando la naturaleza de la pena impuesta, no deben ser afectados.

Tal percepción suele encontrar apoyo tanto en investigaciones empíricas, como en la experiencia "colectiva" de presenciar cotidianamente la forma en que se desarrolla el castigo en nuestra comunidad, particularmente cuando se trata de la experiencia de la cárcel o del encierro.

Junto al empirista crítico se ha levantado, al menos con posterioridad a 1990, un discurso de reforma en el plano normativo. En este sentido, se han dictado reglamentos penitenciarios que recogen en buena medida estándares mínimos de derechos y garantías establecidos en instrumentos internacionales de derechos humanos y que, en términos generales, han compartido una reorientación de la institución penitenciaria siguiendo así las propuestas de los distintos discursos teóricos humanizadores sobre la materia, como aquellas derivadas de la experiencia internacional.

En este sentido, el Reglamento Penitenciario chileno, contenido en el Decreto 518 de 1998, constituye un importante esfuerzo por adaptar la legislación interna a las obligaciones emanadas de los tratados internacionales de derechos humanos ratificados y vigentes en Chile, lo que el propio reglamento señala en su artículo $4^{\circ}$. Es así como cobran gran relevancia normas como la del artículo 10.1 del Pacto Internacional de Derechos Civiles y Políticos y la del artículo 5 de la Convención Americana de Derechos Humanos, que establecen que toda persona privada de libertad deberá ser tratada humanamente y con el respeto debido a la

\footnotetext{
* Abogado, Licenciado en Ciencias Jurídicas y Sociales por la Universidad de Chile, Investigador del Centro de Estudios de la Justicia de la Facultad de Derecho de la Universidad de Chile.
} 
Valenzuela - Estado actual de la reforma al sistema penitenciario...

dignidad inherente al ser humano y que, al igual que todas las personas, no deben ser sometidos a torturas ni a penas o tratos crueles, inhumanos o degradantes

No obstante, el desafío de cumplir con el principio de legalidad en este ámbito se encuentra aún pendiente, así como cuestiones de suma importancia vinculadas a la tutela judicial efectiva de los derechos y garantías del penado. Con la pretensión de generar una instancia político-jurídica de discusión sobre esta materia, en Marzo de 2005 se constituyó una Comisión de Redacción de un Anteproyecto de Ley de Ejecución Penal con el patrocinio del Departamento de Defensa Social del Ministerio de Justicia. Tal Comisión contó con la asistencia de distintos actores de relevancia en la materia, esto es, con profesionales de la propia División de Defensa Social del Ministerio de Justicia, de Gendarmería de Chile, del Instituto de Estudios Judiciales, de la Defensoría Penal Pública, del Ministerio Público, y académicos de la Universidad de Chile, a través del Centro de Estudios de la Justicia de la Facultad de Derecho de esa Universidad. Además, se contó con el importante apoyo técnico y financiero de la Agencia para la Cooperación Técnica alemana, GTZ.

El presente trabajo tiene por función describir de manera más o menos exhaustiva los rasgos más sobresalientes del anteproyecto de ley de ejecución de penas elaborado por la mencionada Comisión Técnica, el que se encuentra aun en fase de discusión para la redacción final. Previamente, no obstante, efectuaremos una breve reseña de la situación actual de la regulación penitenciaria y de los organismos públicos vinculados a la ejecución de las penas privativas de libertad en Chile.

\section{Estado actual de la regulación penitenciaria chilena a la luz de ciertos ejemplos latinoamericanos}

\subsection{Regulación penitenciaria general}

Como se sabe existen normas de carácter penitenciario en los siguientes cuerpos legales y reglamentarios: la Ley Orgánica de Gendarmería, el Código Penal, el Código de Procedimiento Penal de 1906, el Código Procesal Penal, el Reglamento de Establecimientos Penitenciarios de 1998, la Ley de Libertad Condicional y, en un ámbito más específico, la Ley 18.216, el Decreto Ley $\mathrm{N}^{\circ} 409$, de 1932 y el Decreto No 542, de 1943, que crea el Patronato Nacional de Reos. Por ello, puede sostenerse que desde el punto de vista de la red de reglas relevantes para un sujeto que ingresa al sistema penitenciario, la regulación chilena se encuentra atomizada y dispersa. Sin perjuicio de ello cabe señalar que el cuerpo normativo que regula de modo más sistemático y completo esta materia es el Decreto Supremo 518 de 1998, del Ministerio de Justicia, denominado comúnmente "Reglamento de Establecimientos Penitenciarios", cuyo rango jurídico es, sin lugar a dudas, una de las críticas más importantes que se le dirigen. 
$\mathrm{Al}$ ingresar al sistema carcelario, el interno queda sometido a una "relación de derecho público" con el Estado. La ley ha señalado que un órgano administrativo dependiente del Ministerio de Justicia, Gendarmería de Chile, es la institución encargada de "atender, vigilar y rehabilitar a los detenidos o personas privadas de libertad" ${ }^{3}$.

La Ley Orgánica de Gendarmería de Chile describe a esta institución como jerárquica, uniformada, disciplinada y obediente ${ }^{4}$. De estas características resulta evidente el carácter militarizado de la institución, a diferencia de otras instituciones carcelarias existentes en diversos países de Latinoamérica. Así, por ejemplo, el organismo encargado de la ejecución de medidas privativas de libertad de Argentina no está autorizado para portar armas. En el sistema boliviano, se prohíbe expresamente el uso de armas por parte del personal de seguridad encargado de la seguridad interna de los establecimientos penitenciarios.

Las funciones que la ley encomienda a Gendarmería de Chile son, entre otras, dirigir establecimientos penales, cumplir las resoluciones en cuanto al ingreso y libertad de los reclusos, recibirlos y ponerlos a disposición de los Tribunales, custodiar, atender y readaptar a las personas condenadas a penas privativas de libertad, para eliminar su peligrosidad y lograr su reinserción, y asistir a las personas que cumplen sus penas en el medio libre.

Tal orden administrativo no es el único que puede encontrarse en el contexto latinoamericano.

\footnotetext{
${ }^{1}$ Conforme se señala en el actual artículo 2 del Reglamento de Establecimientos Penitenciarios, “(...) Será principio rector de dicha actividad el antecedente que el interno se encuentra en una relación de derecho público con el Estado, de manera que fuera de los derechos perdidos o limitados por su detención, prisión preventiva o condena, su condición jurídica es idéntica a la de los ciudadanos libres."

${ }^{2}$ De acuerdo con el $\mathrm{N}^{\circ} 4$ de los "Principios básicos para el tratamiento de los reclusos, adoptados y proclamados por la Asamblea General en su resolución 45/111, de 14 de diciembre de 1990”, "el personal encargado de las cárceles cumplirá con sus obligaciones en cuanto a la custodia de los reclusos y la protección de la sociedad contra el delito de conformidad con los demás objetivos sociales del Estado y con su responsabilidad fundamental de promover el bienestar y el desarrollo de todos los miembros de la sociedad."

${ }^{3}$ La regla $N^{\circ} 82$ de las "Reglas de las Naciones Unidas para la protección de los menores privados de libertad, adoptadas por la Asamblea General en su resolución 45/113, de 14 de diciembre de 1990" establece que "La administración deberá seleccionar y contratar cuidadosamente al personal de todas las clases y categorías, por cuanto la buena marcha de los centros de detención depende de su integridad, actitud humanitaria, capacidad y competencia profesional para tratar con menores, así como de sus dotes personales para el trabajo."

4 Conforme se señala en el artículo 2 de la Ley 2.859, Orgánica de Gendarmería de Chile, "Gendarmería de Chile, en razón de sus fines y naturaleza, es una institución jerarquizada, uniformada, disciplinada, obediente y su personal estará afecto a las normas que establezcan el estatuto legal respectivo y el reglamento de disciplina que dictará el Presidente de la República”
} 
Valenzuela - Estado actual de la reforma al sistema penitenciario...

En Costa Rica, la institución encargada de los recintos penitenciarios se denomina Dirección General de Readaptación Social, regulada en la Ley N ${ }^{\circ} 4762$ de 1971 (reformada en 2001). Dicha institución tiene por finalidad la ejecución de las medidas y penas privativas de libertad, la custodia y el tratamiento de procesados y condenados, investigar las causas de la criminalidad, recomendar medidas para controlar los efectos de las causas de la criminalidad, el asesoramiento a la autoridad judicial, así como la resolución en los procedimientos administrativos para obtener beneficios y gracias, y estudiar y proponer planes de construcción de establecimientos penitenciarios. Como se ve, existe una gran preocupación en materias criminológicas, lo que no se aprecia en el resto de las legislaciones estudiadas.

Dentro de la estructura orgánica de esta institución se encuentra el Departamento Técnico, que se encarga de brindar apoyo médico, especialmente de siquiatras, sicólogos y odontólogos.

En Bolivia la Ley de Ejecución Penal y Supervisión, N 2298 de 2003 da cuenta de una gran cantidad de organismos encargados de supervigilar, controlar los establecimientos penitenciarios, a saber, la Dirección General de Régimen Penitenciario y Supervisión, la Dirección Nacional de Seguridad Penitenciaria, el Consejo Consultivo Nacional y las Direcciones Departamentales de cada uno de los organismos mencionados lo que, en la práctica, implica una enorme dispersión de responsabilidades.

La Dirección General de Régimen Penitenciario y Supervisión está definida como el organismo que tiene a su cargo la selección, capacitación y especialización del personal que trabaja en los establecimientos penitenciarios. Ahora bien, el director de dicha institución es un policía en servicio activo o en retiro, así como el Jefe de Seguridad Interna y Externa, lo que avalaría la militarización de la institución. No obstante, el personal de la seguridad interna del recinto no puede portar armas, autorizándose el uso de la fuerza física sólo para casos indispensables, y previa intimación.

En Perú se regula esta materia en el Código de Ejecución Penal, Decreto Legislativo $N^{\circ} 654$ de 1991, consagrando al Instituto Nacional Penitenciario (INPE) como el organismo rector del Sistema Penitenciario Nacional. Al considerarse que la administración penitenciaria es una función eminentemente técnica y compleja, se establece que ésta será dirigida por el Consejo Nacional Penitenciario integrado por tres especialistas en asuntos criminológicos y penitenciarios cuyo presidente tendrá funciones ejecutivas. El Consejo tiene como una de sus funciones principales elaborar la política de prevención del delito y tratamiento del delincuente. Se contempla el diseño de una estructura orgánica funcional que permita cumplir con los objetivos y fines del proyecto, enumerándose los órganos que la componen, y cuya organización y funciones están determinados reglamentariamente. 
REJ - Revista de Estudios de la Justicia - No 6 - Año 2005

Por su parte, en la Ley $\mathrm{N}^{\circ} 24.660$ de 1996, argentina, sobre ejecución de la pena privativa de libertad, asigna a la Secretaría de Política Penitenciaria y de Readaptación Social, la función de encargarse de las estadísticas y la coordinación de los establecimientos penitenciarios. En cuanto a la capacitación del personal, destaca una norma que establece que el contenido de la capacitación deberá considerar las Reglas Mínimas de las Naciones Unidas sobre Tratamiento de los Reclusos, las Recomendaciones de las Naciones Unidas sobre la Selección y Formación del Personal Penitenciario adoptadas en Ginebra en 1955 y la Resolución 21 A del Octavo Congreso de las Naciones Unidas, celebrado en La Habana en 1990.

\subsection{Establecimientos penitenciarios en Chile}

El Reglamento de Establecimientos Penitenciarios enumera los principios que rigen al interior de estos recintos, señalando que el fin principal de dicha regulación será la atención, custodia y asistencia orientada a la reinserción de los reclusos. Asimismo, proscribe expresamente la tortura ${ }^{5} 678$.

\footnotetext{
${ }^{5}$ El artículo $1^{\circ}$ de la Declaración contra la Tortura, contenido en la Resolución $N^{o} 3452$, de fecha 9 de diciembre de 1975, establece que: “[a] los efectos de la presente Declaración, se entenderá por tortura todo acto por el cual un funcionario público, u otra persona a instigación suya, inflija intencionalmente a una persona penas o sufrimientos graves, ya sean físicos o mentales, con el fin de obtener de ella o de un tercero información o una confesión, de castigarla por un acto que haya cometido o se sospeche que ha cometido, o de intimidar a esa persona o a otras. No se considerarán tortura las penas o sufrimientos que sean consecuencia únicamente de la privación legítima de la libertad, o sean inherentes o incidentales a ésta, en la medida en que estén en consonancia con las Reglas Mínimas para el Tratamiento de los Reclusos." Por su parte, el artículo $2^{\circ}$ del mismo instrumento señala que "[1]a tortura constituye una forma agravada y deliberada de trato o pena cruel, inhumano o degradante".

${ }^{6}$ El artículo $5^{\circ}$ del Código de Conducta para Funcionarios Encargados de Hacer Cumplir la Ley, aprobado por Res. No 34/169, del 17 de diciembre de 1979 prescribe que: "[n]ingún funcionario encargado de hacer cumplir la ley podrá infligir, instigar o tolerar ningún acto de tortura u otros tratos o penas crueles, inhumanos o degradantes, ni invocar la orden de un superior o circunstancias especiales, como estado de guerra o amenaza de guerra, amenaza a la seguridad nacional, inestabilidad política interna, o cualquier otra emergencia pública, como justificación de la tortura u otros tratos o penas crueles, inhumanos o degradantes".

${ }^{7}$ El artículo 11 de la Convención contra la Tortura y Otros Tratos o Penas Crueles, Inhumanos o Degradantes, adoptada y abierta a la firma, ratificación y adhesión por la Asamblea General en su Resolución 39/46, de 10 de diciembre de 1984 señala que: “[t]odo Estado Parte mantendrá sistemáticamente en examen las normas e instrucciones, métodos y prácticas de interrogatorio, así como las disposiciones para la custodia y el tratamiento de las personas sometidas a cualquier forma de arresto, detención o prisión en cualquier territorio que esté bajo su jurisdicción, a fin de evitar todo caso de tortura".

$8 \mathrm{Al}$ respecto puede tenerse en cuenta el siguiente caso resuelto por la Corte Interamericana de Derechos Humanos (Sentencia Cantoral Benavides, de 18 de agosto de 2000). El señor Cantoral Benavides fue objeto de actos de violencia física y psicológica de parte de las autoridades policiales y por miembros de la Marina durante el período en el cual permaneció detenido e incomunicado en la DINCOTE (Dirección Nacional contra el Terrorismo), todo ello con el fin de obtener su autoinculpación. La sentencia estableció que la incomunicación no tuvo como fin impedir que se
} 
Valenzuela - Estado actual de la reforma al sistema penitenciario...

Se declara el respeto de los derechos que no hayan sido perdidos o limitados expresamente y consagra la presunción de inocencia de los detenidos y sujetos a prisión preventiva?

Asimismo, la norma describe diversos tipos de establecimientos penitenciarios, cuya clasificación es la siguiente:

(1) Centros de Detención Preventiva, en los que se recluye a detenidos y procesados sujetos a prisión preventiva ${ }^{10}$;

entorpeciera la investigación de los hechos, ni constituyó una medida de carácter excepcional; por consiguiente, la incomunicación "arbitraria" que se impuso al señor Cantoral Benavides y las condiciones carcelarias a las que estuvo sometido constituyeron un trato cruel e inhumano que le produjo sufrimientos y perturbaciones psíquicas. Seguidamente, transcribiremos los considerandos pertinentes de la citada sentencia (189 a 191):

“189. El artículo 8 de la Convención Interamericana contra la Tortura consagra en forma expresa la obligación del Estado de proceder de oficio y en forma inmediata en casos como el presente. En este sentido, la Corte ha sostenido que "en los procesos sobre violaciones de los derechos humanos, la defensa del Estado no puede descansar sobre la imposibilidad del demandante de allegar pruebas que, en muchos casos, no pueden obtenerse sin la cooperación del Estado”. El Estado, sin embargo, no actuó en el presente caso con arreglo a esas previsiones.

190. La Corte concluyó, al estudiar la violación por parte del Estado del artículo 5 de la Convención, que el Estado había sometido, a través de sus agentes públicos, a Luis Alberto Cantoral Benavides a tortura y a otros tratos crueles, inhumanos y degradantes (supra párrs. 104 y 106). Por ende, resulta claro que dicho Estado no previno eficazmente tales actos y que, al no realizar una investigación al respecto, omitió sancionar a los responsables de los mismos.

191. En consecuencia, concluye la Corte que el Estado violó, en perjuicio de Luis Alberto Cantoral Benavides, los artículos 2, 6 y 8 de la Convención Interamericana para Prevenir y Sancionar la Tortura.

9 El numeral 15, sobre vigilancia de personas bajo custodia o detenidas, contenido en los Principios básicos de uso de la fuerza y armas de fuego por las personas encargadas de hacer cumplir la ley, aprobados en La Habana, en 1990, señala que: [1]os funcionarios encargados de hacer cumplir la ley, en sus relaciones con las personas bajo custodia o detenidas, no emplearán la fuerza, salvo cuando sea estrictamente necesario para mantener la seguridad y el orden en los establecimientos o cuando corra peligro la integridad física de las personas". Por su parte, el numeral 16 señala que: [1]os funcionarios encargados de hacer cumplir la ley, en sus relaciones con las personas bajo custodia o detenidas, no emplearán armas de fuego, salvo en defensa propia o en defensa de terceros cuando haya peligro inminente de muerte o lesiones graves, o cuando sea estrictamente necesario para impedir la fuga de una persona sometida a custodia o detención que presente el peligro a que se refiere el principio 9." Finalmente, el principio $\mathrm{N}^{\circ} 17$ prescribe que :[1]os principios precedentes se aplicarán sin perjuicio de los derechos, obligaciones y responsabilidades de los funcionarios de establecimientos penitenciarios, tal como se enuncian en las Reglas Mínimas para el Tratamiento de los Reclusos, sobre todo las Reglas 33, 34 y 54.”

${ }^{10}$ El artículo 10 del Pacto de Derechos Civiles y Políticos, aprobado por resol. No 2200, de 16 de diciembre de 1966, que contiene una observación general sobre su aplicación establece que: 1. Toda persona privada de libertad será tratada humanamente y con el respeto debido a la dignidad inherente al ser humano. 2. a) Los procesados estarán separados de los condenados, salvo en circunstancias excepcionales, y serán sometidos a un tratamiento distinto, adecuado a su condición de personas no condenadas; b) Los menores procesados estarán separados de los adultos y deberán ser llevados ante los tribunales de justicia con la mayor celeridad posible para su enjuiciamiento.3. El régimen penitenciario consistirá en un tratamiento cuya finalidad esencial será 
REJ - Revista de Estudios de la Justicia - No 6 - Año 2005

(2) Centro de Cumplimiento Penitenciarios, para condenados a penas privativas de libertad;

(3) Centros de Educación y Trabajo, Centros Abiertos, Agricolas, etc.;

(4) En el caso de menores entre 16 y 18 años, deberían existir recintos completamente separados de los adultos ${ }^{11} 12$

(5) Centros Penitenciarios Femeninos,

(6) Centros de Reinserción Social, para el seguimiento, asistencia y control de condenados en el medio libre.

Desde la perspectiva de las reglas de convivencia interna a las que pueden encontrarse vinculadas las personas privadas de libertad, en el ámbito de la legislación chilena se consideran diversos regímenes carcelarios, a saber:

a. Especial, requiere resolución fundada para que el interno sea incluido en él; su situación debe ser revisada periódicamente y los informes respecto de la mantención o no del recluso en él deben ser enviados trimestralmente a la Dirección Regional de Gendarmería respectiva.

b. Cerrado, en el que priman los principios de seguridad, orden y disciplina. Se considera el establecimiento de horarios, revisión de personas y recintos, además de la posibilidad de intervención y restricción de comunicaciones orales o escritas por razones de seguri$\mathrm{dad}^{13}$.

la reforma y la readaptación social de los penados. Los menores delincuentes estarán separados de los adultos y serán sometidos a un tratamiento adecuado a su edad y condición jurídica.

11 Art. 14.4 del Pacto de Derechos Civiles y Políticos establece:, "[e]n el procedimiento aplicable a los menores de edad a efectos penales se tendrá en cuenta esta circunstancia y la importancia de estimular su readaptación social".

${ }^{12}$ El artículo 29 de las Reglas de las Naciones Unidas para la protección de los menores privados de libertad, adoptadas por la Asamblea General en su Resolución 45/113, de 14 de diciembre de 1990 se expresa que "[e]n todos los centros de detención, los menores deberán estar separados de los adultos a menos que pertenezcan a la misma familia. En situaciones controladas, podrá reunirse a los menores con adultos cuidadosamente seleccionados en el marco de un programa especial cuya utilidad para los menores interesados haya sido demostrada".

${ }_{13} \mathrm{Al}$ respecto puede considerarse el fallo de la Corte Interamericana de Derechos Humanos en el caso "Castillo Petruzzi y otros", de 30 de mayo de 1999. Al respecto transcribimos los considerandos pertinentes: "193.Además, el 7 de enero de 1994, los señores Castillo Petruzzi, Mellado Saavedra y Pincheira Sáez fueron condenados en primera instancia a cadena perpetua, por habérseles encontrado culpables del delito de traición a la patria. Esta condena fue confirmada en última instancia el 3 de mayo de 1994. En esta oportunidad se condenó a la misma pena al señor Alejandro Astorga Valdez. La sentencia de primera instancia establece, además, las condiciones de la reclusión, entre ellas, "aislamiento celular y continuo durante el primer año de la detención y luego con trabajo obligatorio, pena que deberán cumplir [las supuestas víctimas] en celdas unipersonales que el Presidente del Instituto Nacional Penitenciario designe".

194. La Corte ha establecido que el "aislamiento prolongado y la incomunicación coactiva son, por sí mismos, tratamientos crueles e inhumanos, lesivos de la integridad psíquica y moral de la persona y del derecho al respeto de la dignidad inherente al ser humano". 
Valenzuela - Estado actual de la reforma al sistema penitenciario...

c. Semi-abierto, en el que priman las actividades laborales, la capacitación, autodisciplina y confianza.

d. Abierto, en el cual no se contemplan las medidas de los regímenes cerrados, salvo las excepciones que establezca el Director del Establecimiento.

e. De menores, destinado para jóvenes entre 16 y 18 años, que hayan sido declarados con discernimiento. En ellos se desarrollan acciones de educación intensas y, para los condenados, se considera la capacitación laboral y la celebración de convenios con instituciones externas.

En el caso del derecho latinoamericano, el sistema establecido en Costa Rica, por medio de la Ley General Penitenciaria, considera la existencia de un régimen ordinario, uno abierto y uno denominado cerrado o especial. Este último, al igual que el especial chileno, se establece para condenados de extrema "peligrosidad", para los que presentan inadaptación al régimen ordinario o abierto, así como para los sometidos a prisión preventiva que presenten las mismas características de los condenados. En todo caso, los condenados deberán estar separados de los sujetos a prisión preventiva.

En Bolivia, la Ley de Ejecución Penal y Supervisión, regula los siguientes regímenes:

1) Cerrado, en el que existe un estricto control de la actividad del condenado y se establecen limitaciones en sus relaciones externas.

2) Abierto, concebido como un sistema basado en la confianza y en la responsabilidad del condenado, con el objeto de alentarlo al uso de la libertad ofrecida, sin abusar de ella. Se considera la posibilidad de que el condenado sea admitido inmediatamente en el sistema abierto, para favorecer su reinserción. Asimismo, se contempla la posibilidad de ser trasladado a un régimen cerrado, en caso de que la conducta del interno sea desfavorable para los demás condenados.

3) De adolescentes imputables, que considera escolarización o profesionalización del interno. Se elaboran informes trimestrales de evolución de los jóvenes. Las sanciones aplicables a los jóvenes son de $1 / 3$ de las que correspondería a los adultos.

Además, se contemplan los siguientes períodos del sistema progresivo (yo lo pondría si seguir numeración anterior, como algo diferente)

1) De observación y clasificación inicial: Se inicia en el régimen cerrado, por un lapso mínimo de 2 meses, tras el cual determina el Consejo Penitenciario;

2) De readaptación social en ambiente de confianza:. Pretende promover los hábitos y aptitudes para la reinserción social, por aplicación de técnicas individuales y grupales.

3) De prueba. Su objeto es la preparación del condenado para su libertad con autodisciplina y salidas. Este período se cumple siempre en el régimen abierto. 
4) Libertad condicional. Se define como el cumplimiento en libertad del saldo del tiempo de la condena impuesta en la sentencia. Concede este beneficio el Juez de Ejecución Penitenciaria, previo informe del Director del Establecimiento. Asimismo, se establecen como requisitos para su obtención, los siguientes:

a) haber cumplido los dos tercios del tiempo de la condena;

b) presentar buena conducta y no haber sido sancionado por faltas graves o muy graves, en el último año; y

c) presentar vocación para el trabajo.

\section{Principales aspectos para la reforma penitenciaria chilena}

\subsection{Existencia de una ley de ejecución de penas}

Se sostiene que el principio de legalidad de las penas, que en el caso chileno puede ser construido a partir del artículo 19 número 3 incisos $6^{\circ}$ y $7^{\circ}$ de la $\mathrm{CPR}^{14}$, debe abarcar los momentos de la conminación, adjudicación y ejecución de la pena o medida de seguridad ${ }^{15}$, pues en todas estas fases se garantiza a las personas la intangibilidad de sus derechos fundamentales cuando se trata del ejercicio del ius puniendi estatal o, al menos, de aquellos que no son afectados por la sanción impuesta en la sentencia definitiva. El principio de legalidad en este ámbito asegura, pues, el fundamento democrático de las restricciones a los derechos y garantías de los sujetos y el carácter cognoscitivo de las prohibiciones y mandatos punitivos Sin embargo, en el derecho chileno es manifiesta la infracción de la garantía de ejecución legal de las penas en el ordenamiento jurídico chileno, pues no hay un cuerpo normativo con rango de ley que regule todo lo concerniente a la ejecución de las penas y medidas de seguridad, agravada esta situación por la inexistencia de una instancia jurisdiccional exclusiva que resuelva los conflictos que surgen entre los internos y la Administración penitenciaria o de los internos entre sí.

En efecto, es evidente que en el momento de la conminación penal,, el principio de legalidad se encuentra satisfecho en el Código Penal y las leyes penales especiales ${ }^{16}$. En tanto, el momento de la adjudicación legal de la pena se

\footnotetext{
14 Artículo 19 número 3 incisos $6^{\circ}$ y $7^{\circ}$ : "Ningún delito se castigará con otra pena que la que señale una ley promulgada con anterioridad a su perpetración, a menos que una nueva ley favorezca al afectado. Ninguna ley podrá establecer penas sin que la conducta que se sanciona esté expresamente descrita en ella".

15 Por todos ver, Silva Sánchez, Jesús, "Perspectivas sobre Política Criminal moderna”, Ed. Ábaco, Buenos Aires, 1999, páginas 59 a 65.

16 Sin perjuicio de las objeciones que puedan plantearse a los DFL y DL dictados durante el régimen militar a los que se reconoce, en general, que satisfacen el principio de legalidad penal. Especialmente relevante es la circunstancia que la regulación de las medidas de seguridad y su
} 
Valenzuela - Estado actual de la reforma al sistema penitenciario...

cumple con el Código Procesal Penal, vigente desde el 12 de Octubre de 2000, y demás leyes complementarias.

Por el contrario, y como ya advirtiéramos, en el ámbito de la ejecución administrativa de la pena la infracción al principio de legalidad es fácilmente constatable. Así, en el caso chileno la regulación "dura" en la materia puede encontrarse sólo en el nivel reglamentario, específicamente en el Decreto Supremo 518 del Ministerio de Justicia de 21 de agosto de 1998, comúnmente denominado "Reglamento de Establecimientos Penitenciarios", pues el Código Penal y otras leyes penales especiales sólo regulan aspectos generales de la ejecución penitenciaria y de otras sanciones previstas en el ordenamiento jurídico chileno.

Con ello se acusa la urgente necesidad de someter a la deliberación democrática la determinación del "para qué" y "cómo" debe padecerse la pena en el ámbito penitenciario nacional, de modo que exista una mayor coherencia político-criminal en los diferentes niveles en los que la pena cumple una función en el sistema social. Desde esta perspectiva, no basta la declaración de una función resocializadora de la pena si las diversas instancias ideológicas y operativas del sistema no actúan de un modo coherente con dicho propósito.

Por otro lado, y desde una perspectiva liberal democrática la pena presupone la calidad de "ciudadano" de aquellos que pueden ser reprochados por medio de ella. En efecto, sólo pueden ser responsabilizados penalmente aquellos sujetos que pueden ser reconocidos como agentes con capacidad de "yo", es decir, aquellos que pueden asumir decisiones de manera autónoma en virtud de su capacidad de comunicación. El reproche jurídico-penal importa la posibilidad (y la capacidad) de defraudar el mensaje comunicativo de abstención o actuación que las normas penales comportan. En suma, sólo es posible plantear la defraudación de una expectativa normativa respecto de quien razonablemente puede esperarse que comprende eficazmente el mensaje normativo que contiene la ley y que puede actuar conforme a él ${ }^{17}$.

En este contexto debe tenerse a la vista la inconsistencia regulativa derivada del artículo 17 de la Constitución Política de la República ${ }^{18}$, pues en

ejecución siempre se ha hecho, en nuestro país, en las leyes de procedimiento penal; actualmente, en el Código Procesal Penal, artículos 455 a 465 y 481a 482.

17 Sobre el particular, cfr. Mañalich Raffo, Juan Pablo, "Pena y ciudadanía", ponencia presentada en el II Congreso de Teoría y Derecho Constitucional”, disponible en www.congreso.uchile.cl.

${ }^{18}$ La citada disposición constitucional establece que: "[l]a calidad de ciudadano se pierde:

$1^{\circ}$.- Por pérdida de la nacionalidad chilena;

$2^{\circ}$.- Por condena a pena aflictiva, $y$

$3^{\circ}$.- Por condena por delitos que la ley califique como conducta terrorista.

Los que hubieren perdido la ciudadanía por la causal señalada en el número $2^{\circ}$. podrán solicitar su rehabilitación al Senado, una vez extinguida su responsabilidad penal. Los que hubieren perdido la ciudadanía por la causal prevista en el número $3^{\circ}$. sólo podrán ser rehabilitados en virtud de una ley de quórum calificado, una vez cumplida la condena. 
tanto se niegue la posibilidad de participación en el tráfico de decisiones de una persona por el hecho de ser condenado a una determinada pena no sólo hace inválido el juicio de reproche a su respecto (deja de tener un fundamento comunicativo) sino que priva de todo contenido a la pretensión resocializadora. ${ }^{19}$

\subsection{Existencia de control administrativo y jurisdiccional en el ámbito penitenciario}

En el ámbito carcelario existe un serio y constante riesgo de afectación ilegítima de derechos fundamentales de la persona. En efecto, es habitual comprobar que junto con la privación o restricción de la libertad ambulatoria que determina la imposición de una pena privativa o restrictiva de la libertad se perturben indirectamente otros derechos garantizados constitucionalmente, como la intimidad o la libertad de información o expresión, circunstancia que es aceptada o tolerada por los propios afectados y por aquéllos que tienen el deber de proteger tales derechos.

En este mismo contexto se sitúa el peligro de vulneración del principio de proporcionalidad en las diversas actuaciones que realizan los funcionarios de la administración penitenciaria, al no existir una definición estricta de los derechos y deberes entre el individuo condenado y el Estado en este especial ámbito de sujeción, ${ }^{20}{ }^{21}$ con una regulación del modo de preservación y tutela de los derechos no afectados por la pena.

En consideración a ello, la actual propuesta de reforma al sistema penitenciario busca configurar un sistema legal de control específico de la actividad administrativa de ejecución penal que se conforme a la idea contenida en el esquema siguiente:

\footnotetext{
$19 \mathrm{Al}$ respecto cfr. Mañalich Raffo, Juan Pablo, "Pena y ciudadanía", Ponencia presentada en el II Congreso de Teoría y Derecho Constitucional”, en www.congreso.uchile.cl.

${ }^{20}$ Junto a esto debe considerarse la inexistencia en el ordenamiento jurídico chileno de tribunales y procedimientos específicamente abocados a lo "contencioso-administrativo". Sobre el particular, vid. Moraga Klenner, Claudio, "La Jurisdicción contenciosa administrativa. El proceso jurisdiccional administrativo", en Estado de Derecho y reformas a la Justicia, editado por el Centro de Estudios de la Justicia de la Facultad de Derecho de la Universidad de Chile, el Heidelberg Center para América Latina de la Universidad de Heidelberg, la California Western School of law, y Agencia para la cooperación técnica alemana, GTZ, Santiago, 2005, páginas 106 y siguientes.

${ }^{21} \mathrm{Al}$ respecto puede considerarse lo señalado por Johannes Feest, en "La protección jurídica en el ámbito penitenciario", en Cd-Rom "Acceso a la Justicia en el ámbito penitenciario", editado por GTZ, 2004: "Desde el siglo IX, existen en Alemania tribunales administrativos especiales, a los cuales pueden acudir los ciudadanos con una demanda. Sin embargo, la administración de justicia está excluida de este reglamento. Tal vez hubiera sido mejor desistir de este privilegio de la administración de justicia y abrirles a los presos el acceso a los tribunales administrativos comunes, pero no fue asi."
} 


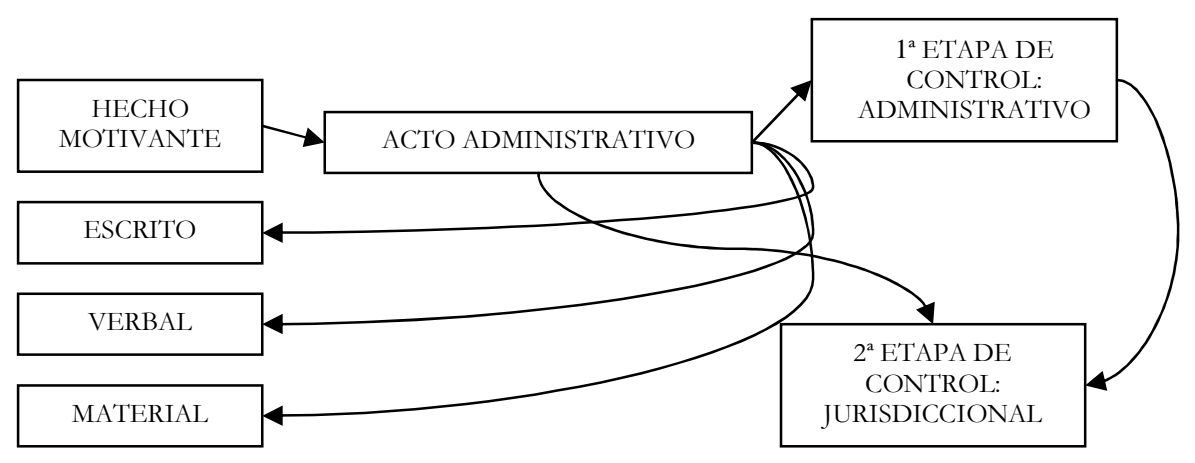

Conforme al esquema propuesto, en el ámbito penitenciario puede asumirse una definición diferenciada o específica de "acto administrativo".Tal definición debiera encontrarse estrechamente vinculada a la posibilidad de afectación de derechos del interno o de terceros por medio de una decisión de la administración penitenciaria. Se propone abarcar todas las formas o medios a través de los cuales puede manifestarse un acto administrativo en el ámbito penitenciario; sea de carácter escrito (mediante documento manuscrito, mecanografiado, electrónico, o cualquier otro medio que permita conservar en forma fidedigna la decisión adoptada y sus fundamentos), oral (mediante un acto de habla que implique una decisión) o material (por medio de una acción comunicativa que no adopte ninguna de las formas anteriores, pero que contenga una decisión asimilable).

De este modo y por regla general, un acto arbitrario o ilegal de la administración penitenciaria desencadenará un primer control de carácter interno que podrá ser inmediatamente seguido por un control "judicializado" o externo del mismo acto, control que se propone sea ejercido por un juez especializado en el área penitenciaria, esto es, jurisdicción especializada que constituye una de las propuestas centrales del Anteproyecto. Sin perjuicio de lo anterior, el Anteproyecto contempla la posibilidad de recurrir directamente ante el juez de ejecución penal cuando este estime que la persona privada de libertad no está en condiciones de ejercer los derechos y garantías consagrados en la Constitución Política, en los instrumentos internacionales de derechos humanos ratificados por Chile o en las leyes, siguiendo en éste punto la decisión adoptada por el legislador en el artículo 10 del Código Procesal Penal, al referirse en forma genérica a la cautela de garantías dentro del proceso penal. ${ }^{22}$

${ }^{22}$ El artículo 10 del Código Procesal Penal prescribe: “Cautela de garantías. En cualquiera etapa del procedimiento en que el juez de garantía estimare que el imputado no está en condiciones de ejercer los derechos que le otorgan las garantías judiciales consagradas en la Constitución Política, 
Sin duda la propuesta de una jurisdicción especializada para la resolución de los conflictos que se susciten en el ámbito de la ejecución de las penas constituye una de las demandas de reforma al sistema penitenciario más generalmente planteada. El principal apoyo institucional a la propuesta de un órgano jurisdiccional especializado se halla en el artículo 25 letra b) del Pacto de San José de Costa Rica ${ }^{23}$.

En este sentido y en el marco del Anteproyecto de reforma al sistema penitenciario se pretende introducir al ordenamiento jurídico chileno un tribunal emparentado con uno propio de los sistemas que contemplan una jurisdicción contencioso administrativo, desechando la vinculación, ya clásica, entre el juez de ejecución de penas y los jueces con competencia en lo criminal. Como señala Feest: "parecería más conveniente, que en estos casos se tratase de jueces administrativos y no de jueces penales, pues éstos últimos tienden a ver en el preso al acusado y no al querellante. Tampoco tienen la costumbre de promover un acuerdo entre las partes. Sin embargo, precisamente respecto al régimen penitenciario, sería mucho más conveniente lograr un acuerdo o una mediación en vez de una resolución judicial. Bajo las condiciones de una institución total, una resolución judicial pocas veces logra resolver el conflicto, al contrario, despierta en la parte perdedora las ganas de cobrar venganza y tiende a agudizar el conflicto"24.

En este sentido se propone organizar la competencia del juez de ejecución de penas, por regla general, en la iniciativa del sujeto interno o afectado por el acto administrativo -con la hipótesis excepcional contenida en el artículo 22 del

en las leyes o en los tratados internacionales ratificados por Chile y que se encuentren vigentes, adoptará, de oficio o a petición de parte, las medidas necesarias para permitir dicho ejercicio.

Si esas medidas no fueren suficientes para evitar que pudiere producirse una afectación sustancial de los derechos del imputado, el juez ordenará la suspensión del procedimiento y citará a los intervinientes a una audiencia que se celebrará con los que asistan. Con el mérito de los antecedentes reunidos y de lo que en dicha audiencia se expusiere, resolverá la continuación del procedimiento o decretará el sobreseimiento temporal del mismo.

${ }^{23}$ El articulo 25 de la Convención Americana de Derechos Humanos, en el acápite sobre protección judicial prescribe que: " 1 . Toda persona tiene derecho a un recurso sencillo y rápido o a cualquier otro recurso efectivo ante los jueces o tribunales competentes, que la ampare contra actos que violen sus derechos fundamentales reconocidos por la Constitución, la ley o la presente Convención, aun cuando tal violación sea cometida por personas que actúen en ejercicio de sus funciones oficiales."

"2. Los Estados partes se comprometen:

a. A garantizar que la autoridad competente prevista por el sistema legal del Estado decidirá sobre los derechos de toda persona que interponga tal recurso;

b. A desarrollar las posibilidades de recurso judicial, y

c. A garantizar el cumplimiento, por las autoridades competentes, de toda decisión en que se haya estimado procedente el recurso.

${ }^{24}$ Feest, Johannes, "La protección jurídica en el ámbito penitenciario", en Cd-Rom "Acceso a la Justicia en el ámbito penitenciario”, Editado por GTZ, 2004. 
Valenzuela - Estado actual de la reforma al sistema penitenciario...

Anteproyecto en revisión- abarcando todas aquellas decisiones que afectan, con especial intensidad, los derechos o la situación de los privados de libertad. ${ }^{25}$

\subsection{Procedimiento ante el juez de ejecución}

Acorde con la idea de establecer un juez de ejecución penal que desde el punto de vista orgánico y procedimental se asemeje a un tribunal contencioso administrativo, en el contexto del actual Anteproyecto de ley se propone el diagrama siguiente:

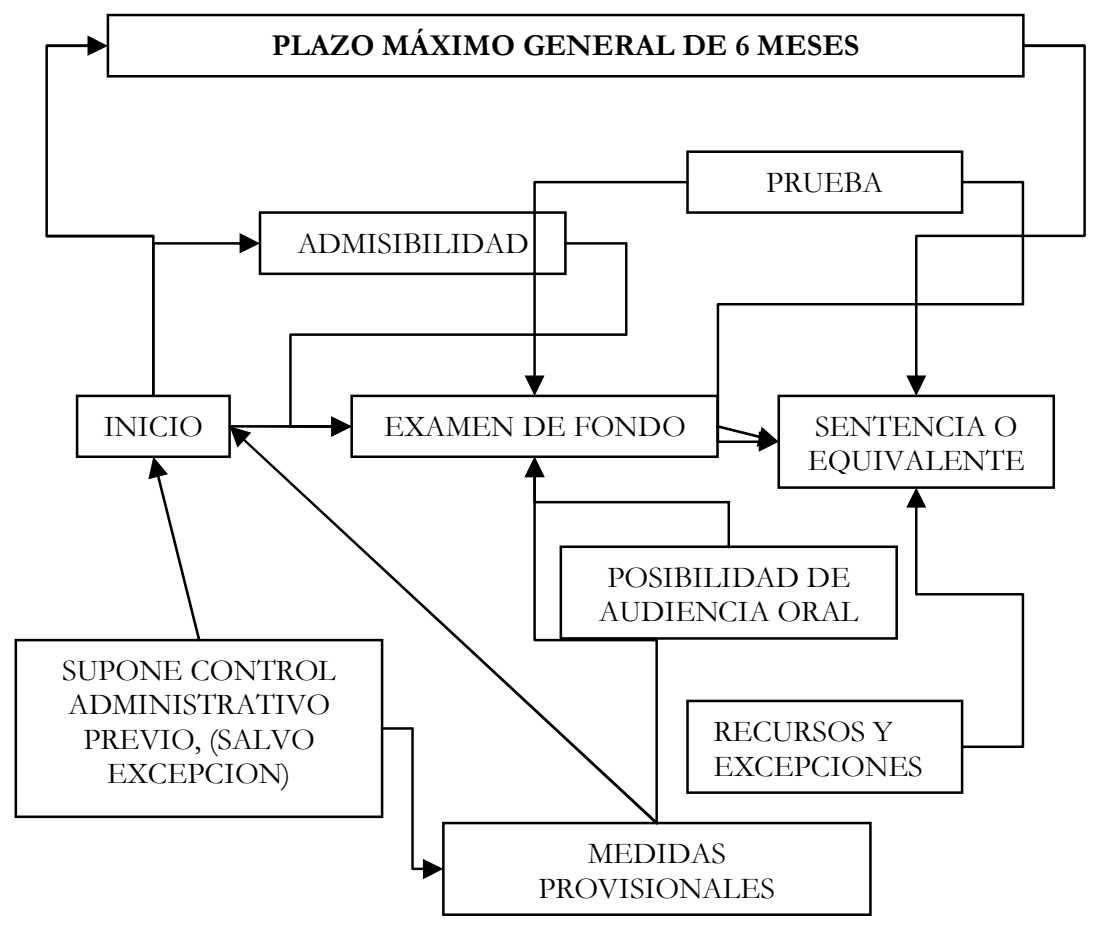

25 Propuesta normativa de Control Jurisdiccional en el ámbito penitenciario, aprobada en la Comisión de redacción de anteproyecto de Ley de Ejecución Penal, anteproyecto en revisión: "El Juez de Ejecución Penal tendrá competencia para conocer y resolver las solicitudes y reclamos que se susciten a propósito de:

a. Cualquier acto que afecte las garantías y derechos del condenado, preso o sujeto a medida de seguridad por parte de los organismos del estado encargados de su ejecución o de los terceros que intervengan en ella, tales como los que surjan del régimen disciplinario, los traslados, entre otros.

b. Las modalidades de la ejecución de las penas; tales como el tratamiento penitenciario, los permisos de salida; condonación de multas, arresto sustitutorio, entre otros;

c. La revisión de las decisiones relativas a medidas alternativas a la pena privativa de libertad;

d. La modificación de la ejecución de la pena impuesta, especialmente las decisiones relativas a la libertad condicional y a la rebaja de condena;

e. La ejecución de las medidas de seguridad y de su cesación;

f. La ejecución de las medidas cautelares personales que contempla el Código Procesal Penal y de cualquier medida de apremio;

g. Todas aquellas materias que la ley le encomiende." 
Conforme al esquema propuesto, el procedimiento ante el juez de ejecución de penas encuentra como rasgos definitorios los siguientes:

1) Se trata de un procedimiento esencialmente contencioso administrativo;

2) Contempla la asunción de ciertas medidas provisionales tendientes a poner remedio inmediato a situaciones de afectación de derechos fundamentales;

3) Supone, por regla general, un control administrativo previo (salvo la excepción de la cautela de garantías y derechos);

4) Si bien el procedimiento tiende a ser escrito no excluye y posibilita la existencia de audiencias orales ante el juez de ejecución;

5) Cuenta con un plazo máximo de realización de seis meses.

De esta manera en el ámbito penitenciario nos encontramos ante un caso de aplicación de facultades y potestades administrativas especificadas del Estado $^{26}$ y la revisión judicial opera como un mecanismo de control externo a la administración fundado en el principio republicano de separación de los poderes del estado y la necesidad de contemplar frenos y contrapesos en áreas de la administración especialmente vulnerables para los derechos de las personas. Así, según se ha señalado en "Manual de buena práctica penitenciaria": "[I]os tribunales también tienen el poder inherente y el deber de realizar la revisión judicial de la administración de disciplina y castigos en instituciones penales con el objeto de asegurar que sean conforme a la ley y no arbitrarios o injustos" ${ }^{27}$.

Dicho órgano jurisdiccional especializado debiera contar con competencia en todas las materias referidas al cumplimiento de las penas y al otorgamiento de beneficios penitenciarios, para resolver sobre las denuncias y peticiones que realicen los condenados con ocasión de la ejecución penal y también cualquier solicitud sobre las medidas alternativas a las penas privativas de libertad $^{28}$. Se propone así un procedimiento esencialmente administrativo-judicial

\footnotetext{
${ }^{26} \mathrm{Al}$ respecto debe considerarse lo señalado por Catalina Escuín Palop, en su Curso de Derecho Administrativo, Lección 9, "El procedimiento administrativo", 2003, Tirant Lo Blanch On Line: "El procedimiento administrativo se puede definir como el cauce que tiene la Administración pública para ejercer sus potestades administrativas. La variedad de potestades administrativas y la multiplicidad de sectores en los que la Administración actúa investida de su poder de imperio, determina que la referencia al procedimiento administrativo en singular sea una simplificación de la realidad jurídica, pues no existe uno sino muchos procedimientos administrativos"

27 VV.AA., "Manual de buena práctica penitenciaria" en Reforma penal Internacional, $2^{\circ}$ ed., Costa Rica, 2002, p. 59.

${ }^{28}$ Vid. por todos, "Informe de la Comisión especial investigadora de los problemas carcelarios del país", publicado en El sol en la ciudad, Comisión Chilena de Derechos Humanos, 1993, p. 243 y ss., el que en su letra " $E$ ", 2 ' párrafo, referido al control jurisdiccional de los recintos penitenciarios, expresa: "Parece lo más adecuado la creación de tribunales especializados, a lo menos en primera instancia, con competencia para controlar el cumplimiento del régimen penitenciario, para velar
} 
Valenzuela - Estado actual de la reforma al sistema penitenciario...

(así por ejemplo, para el caso de aplicación de una medida disciplinaria en contra de un interno o de reclamo en contra de un funcionario penitenciario) para distinguirlo del procedimiento criminal que debe iniciarse por hechos que revistan el carácter de delito, cuya denuncia debe hacerse a la policía o al Ministerio Público. Esta distinción encuentra apoyo institucional en la norma contenida en el artículo $83^{29}$ de la Constitución Política de la República, primera parte. ${ }^{30}$

La conveniencia de contar con un juez especializado en materias penitenciarias parece ofrecer mayores ventajas que mantener el modelo actualmente vigente del juez de garantía (conforme al mencionado artículo 466 $\mathrm{CPP}$ ). En efecto, a la crítica previsible de la enorme competencia atribuida a los jueces de garantía en el nuevo sistema procesal penal, que reduce sensiblemente su capacidad para ejercer eficazmente esta función, se añade la falta de capacitación especializada en temas penitenciarios o la problemática aproximación hacia la persona del condenado cuando ha estado en contacto con él en etapas previas del proceso penal. En este sentido, y refiriéndose a la experiencia alemana, Feest ha afirmado que los jueces penales "(...) tienden a ver en el preso al acusado y no al querellante. Tampoco tienen la costumbre de promover un acuerdo entre las partes. Sin embargo, precisamente respecto al régimen penitenciario, sería mucho más conveniente lograr un acuerdo o una mediación en vez de una resolución judicial. Bajo las condiciones de una institución total, una resolución judicial pocas veces logra resolver el conflicto, al contrario, despierta en la parte perdedora las ganas de cobrar venganza y tiende a agudizar el conflicto"31.

En todo caso, esta crítica no nos parece totalmente de recibo. En efecto, el juez de garantía, en nuestro sistema, está siendo entrenado en salidas alternativas o procedimientos especiales que reconocen una fuerte dosis de negociación entre las partes; pero, por otro lado, la mediación no nos parece una vía adecuada para la solución de conflictos entre los internos y los funcionarios o autoridades a cargo de su vigilancia, pues no existe una relación básica de igualdad ni de condiciones que asegure la voluntariedad y libertad del consentimiento de aquéllos. En otros términos, si existe un escenario donde las dudas relativas al pie de igualdad que debe servir de fundamento a una solución en alguna medida autocompositiva del conflicto ese escenario es aquel en que se enfrenta de un lado el ciudadano y de otro el Estado.

por los derechos de los sujetos sometidos a prisión y otros sistemas de control para resolver sobre las medidas alternativas a las penas privativas de libertad y sobre los regímenes de libertad parcial o total posibles de ser otorgados durante el cumplimiento de la condena”.

${ }^{29}$ Debe tenerse presente la modificación en la numeración de la C.Pol. chilena realizada por medio del D.S. 100 de 17 de septiembre de 2005, sustituyendo la designación "80 A" por " 83 ".

${ }^{30} \mathrm{El}$ artículo 83, primera parte, de la CPR señala que: "Un organismo autónomo, jerarquizado, con el nombre de Ministerio Público, dirigirá en forma exclusiva la investigación de los hechos constitutivos de delito, los que determinen la participación punible y los que acrediten la inocencia del imputado y, en su caso, ejercerá la acción penal pública en la forma prevista por la ley.”

${ }^{31}$ Feest, Johannes, íbid. 
En el ámbito del procedimiento administrativo-judicial reviste especial interés el establecimiento de reglas amplias de admisibilidad y ejercicio de las facultades y derechos por parte de los intervinientes. De esta manera se destaca la necesidad de evitar el rechazo de las solicitudes por vicios de forma que redunda en ausencia de acceso a la justicia por parte de las personas sujetas a alguna pena o medida de las contempladas en el Anteproyecto. Junto al amplio concepto de interesado habilitado para provocar la actuación del juez de ejecución se considera, en consonancia con la idea recién expresada, una regla de exención de la obligación de comparecencia patrocinada por abogado.

Por otro lado, y para los efectos de comprender dentro del ámbito de competencia de los jueces de la jurisdicción penitenciaria a cualquier tercero comprometido, directa o indirectamente, con la ejecución de penas y medidas privativas de libertad o con su supervigilancia, se contempla una regla que les atribuye expresamente la calidad de intervinientes. Esta regla es especialmente relevante si se piensa en el fenómeno, creciente en la actualidad, de concesión a empresas privadas de la gestión y administración de las cárceles estatales. Tal intervención, aunque no diga relación directa con la supervigilancia de los reclusos, puede tener importante incidencia en la afectación de los derechos y garantías no afectados por la pena o medida y que les son reconocidos constitucionalmente.

\section{Diagnóstico de la reforma}

Sin duda que un análisis acabado del anteproyecto de ley de ejecución de penas excede con creces la extensión del presente trabajo. Por ello, estimamos preferible efectuar una exposición sintética acerca de los rasgos y orientación principales de la reforma pretendida en el ámbito penitenciario.

En primer lugar, que un objetivo declarado del anteproyecto es la regulación centralizada y sistematizada, en un mismo cuerpo legal, de toda la normativa concerniente a la ejecución de las penas y medidas contempladas en el ordenamiento jurídico chileno, especialmente las que implican una privación o restricción de la libertad ambulatoria. Con ello se quiere superar la enorme dispersión de la regulación actualmente vigente, generando un cuerpo normativo con pretensiones de coherencia interna y exhaustividad, y que recoja los principios y reglas mínimas elaboradas por los instrumentos internacionales de derechos humanos en el ámbito de la ejecución penitenciaria. Es importante aclarar que, siguiendo modelos del derecho comparado, el anteproyecto opta por incorporar en su regulación el cumplimiento de toda medida que suponga una privación o restricción de la libertad, pues se trata de aspectos no habitualmente regulados por la ley o de manera muy sucinta (por ejemplo, la ejecución de la medida de prisión preventiva en el artículo 150 del Código Procesal Penal). En este entendido, se regulan instituciones no propiamente penitenciarias como la ejecución de las medidas cautelares personales privativas y restrictivas de libertad que pueden 
Valenzuela - Estado actual de la reforma al sistema penitenciario...

dictarse en un proceso penal o de otra índole (arrestos, detención, prisión preventiva) y, evidentemente, la medida de seguridad de internación en un establecimiento psiquiátrico (artículo $457 \mathrm{CPP}$ ), eso sí debiendo seguirse los lineamientos establecido en el Párrafo $4^{\circ}$ del Título VIII del Libro IV del Código Procesal Penal. Debemos decir que en el estado actual del anteproyecto esta pretensión no se encuentra satisfecha, es decir, si bien en el nivel del ámbito de aplicación se busca abarcar todas las formas de restricción o privación de libertad relevantes tanto en el ámbito del proceso penal, como en el ámbito penitenciario, no encontramos normas que desarrollen el modo de ejecución y control sobre las medidas cautelares privativas o restrictivas de libertad o apremios. Esperamos que en el transcurso de la revisión del anteproyecto se generen aquellos apartados pendientes.

En el diseño de la propuesta legal es central la importancia que reviste el establecimiento de un Juez o Tribunal de Ejecución de Penas, esto es, un órgano jurisdiccional exclusivamente abocado a resolver las solicitudes y contiendas que planteen los condenados a una pena o sometidos a una medida durante o con ocasión del cumplimiento de las mismas y que afecten sus derechos fundamentales. Establecer una judicatura especializada en este ámbito viene a solucionar uno de los cabos sueltos que existen en Chile a propósito de las materias que son de competencia del juez de garantía. Tal como señala Horvitz: "En efecto, resulta altamente criticable que, siendo la propia autoridad administrativa la que dicta dichos reglamentos, sea al mismo tiempo la que se encuentre encargada de aplicarlos y cumplirlos, dejándose esta materia entregada al autocontrol y vulnerándose el principio republicano de separación de los poderes. Por ello resulta de gran relevancia la norma contenida en el artículo 466 CPP, cuando establece que durante la ejecución de la pena o de la medida de seguridad, podrán intervenir ante el competente juez, de garantía el ministerio público, el imputado y su defensor ${ }^{32}$

En efecto, el artículo 466 del Código Procesal Penal, ubicado en el Título VIII del Libro IV relativo a los Procedimientos Especiales y Ejecución y cuyo epígrafe indica "Intervinientes", señala que "durante la ejecución de la pena o medida de seguridad, solo podrán intervenir ante el competente juez de garantía el ministerio público, el imputado y su defensor". El inciso segundo agrega que "el condenado o el curador, en su caso, podrán ejercer durante la ejecución de la pena o medida de seguridad todos los derechos y facultades que la normativa penal o penitenciaria le otorgare".

La competencia de los jueces de garantía en materia penitenciaria viene reforzada por el artículo 14 del Código Orgánico de Tribunales, que atribuye a aquéllos, en su letra f), "[h] acer ejecutar las condenas criminales y las medidas de seguridad, y resolver las solicitudes y reclamos relativos a dicha ejecución, de conformidad a la ley procesal penal (...)”.

32 Horvitz, María Inés y López, Julián, Derecho Procesal Penal chileno, Tomo II, Editorial Jurídica de Chile, 2004, página 589. 
Los jueces de garantía tienen una gran cantidad de materias entregadas a su conocimiento y resolución en el ámbito procesal, lo cual constituye una razón para que el anteproyecto manifieste su opción por un órgano jurisdiccional especializado en materias penitenciarias y exclusivamente abocado a las mismas, no sólo porque es la única forma de garantizar la eficiencia en su operatividad sino porque con ello se otorga relevancia a una parcela del derecho fuertemente desplazada de la agenda pública y en que los derechos fundamentales de las personas son cotidianamente vulnerados. De esta forma se podría dar una solución efectiva y legítima a la carencia de un "segundo nivel de control" sobre las actuaciones ilegítimas de la autoridad que se realicen en el desarrollo de la actividad penitenciaria.

Otro punto de especial importancia está dado por la re-estructuración de las condiciones de vida que se desarrollan en el interior de las cárceles. Por la vía de la recepción de la idea de "planificación de la ejecución" presente en el proyecto de reforma puede generarse la necesaria modificación en el modo de entender la actividad penitenciaria, la que -conforme a su actual configuración- debe estar orientada hacia el otorgamiento de elementos para la rehabilitación o reinserción de los penados. En este sentido debe, una vez más, apuntarse al desarrollo de las dos actividades principales sobre las cuales debe realizarse la vida al interior de los recintos penitenciarios, esto es, el trabajo y la educación, pero de un modo en que se asegure su oferta por parte del Estado.

Finalmente, cabe destacar el planteamiento de una institución fundamental desde el punto de vista de la protección de los derechos humanos en el ámbito de las cárceles, la Defensoría Penitenciaria, análoga a su homónimo genérico, el "ombudsman". El anteproyecto chileno ha seguido, en este punto, el modelo argentino, al optar por la generación diferenciada de un defensor de derechos fundamentales, esto es, uno concentrado únicamente en el ámbito penitenciario.

En este sentido, pareciera conveniente contar con una institución que sea independiente, cuyo sistema de nombramiento esté radicado esencialmente en el parlamento, y que cuente con flexibilidad para situarse como un censor del respeto a las garantías aseguradas por la constitución respecto de las personas que sufren el padecimiento de una pena o medida estatal privativa o restrictiva de libertad. 